\title{
Detection rate of common intestinal parasites in end stage renal disease patients under maintenance hemodialysis in Benha University Hospital, Egypt
}

Article

\author{
Ayman M Elbadawy ${ }^{1}$, Ahmed Ezzat ${ }^{1}$, Asmaa A Elkholy ${ }^{2}$ \\ Departments of Internal Medicine ${ }^{1}$ and Medical Parasitology ${ }^{2}$, Faculty of Medicine, Benha \\ University, Egypt
}

\begin{abstract}
Background: Several parasites are responsible for life threatening infections in immunocompromised patients including those with chronic renal diseases. Determination of enteroparasitosis prevalence in patients with end stage renal disease (ESRD) experiencing hemodialysis (HD) showed elevated rates of infection, primarily by protozoa.

Objectives: To investigate the common intestinal parasites among patients with ESRD undergoing HD in Benha University Hospital.

Subjects and Methods: This case-control research was performed on 57 patients subjected to HD and 60 apparently healthy people as control group with no history of kidney disorders or other immunosuppressive conditions in the control group. Age of participants ranged from 20-70 years in both groups. Three consecutive fresh fecal samples from all participants were obtained after completion of the questionnaire and examined macroscopically and microscopically to identify various stages of common pathogenic intestinal parasites using iodine and modified Ziehl-Neelsen stains to detect protozoa.

Results: The total rate of parasite infection was 68.4\% and 48.3\% in ESRD patients and control group, respectively. The discrepancies between the two groups were statistically significant. E. histolytica/E. dispar was the commonest parasite compared to other parasites in the two groups.

Conclusion: In ESRD patients, a high detection rate of intestinal parasites was reported which can lead to severe complications in these patients being immunocompromissed individuals. Hence, stool examintion should also be integrated into the standard clinical care of these patients.
\end{abstract}

Keywords: end stage renal failure, enteroparasitosis, hemodialysis.

Received: 29 December, 2020, Accepted: 31 January, 2021.

Corresponding Author: Asmaa A Elkholy, Tel.: +20 1030505006, E-mail: asmaakholy787@gmail.com

Print ISSN: 1687-7942, Online ISSN: 2090-2646, Vol. 14, No. 1, April, 2021.

\section{INTRODUCTION}

Among the most important causes of morbidity and mortality worldwide are intestinal parasitic infections (IPIs), especially in developing countries ${ }^{[1,2]}$. Protozoan organisms or helminths may be the cause. In tropical and subtropical regions of the developing world, the most prevalent parasites include $G$. lamblia, E. histolytica/E. dispar, Cryptosporidium spp, A. lumbricoides, A. duodenale, $N$. americanus, and $T$. trichiura $^{[3,4]}$.

Enteric infections represent a significant risk to immunocompromised patients including chronic kidney diseases patients ${ }^{[2]}$. In immunocompromised patients, infections that cause auto-limited diarrhea in immunocompetent individuals can cause profuse diarrhea, usually followed in some cases by weight loss, anorexia, malabsorption syndrome and also fever and abdominal pain. Parasites such as Cryptosporidium spp., Enterocytozoon bieneusi, Encephalytozoon intestinalis and S. stercoralis can spread to many organs in such patients. These organs includes the bronchi, liver, and bile ducts, causing symptoms that are unique to the affected organ ${ }^{[5-8]}$.
Renal failure is an immunosuppressive disorder that makes patients, more vulnerable to infection by opportunistic protozoan parasites ${ }^{[9]}$. HD patients suffer from humoral and cell-mediated immune defects and have abnormalities in the acquired immune response to a number of antigens ${ }^{[10,11]}$. Endstage renal failure contributes to weakened cellmediated immunity owing to malfunction of cluster of differentiation 4 (CD4+) T cells and lymphopenia ${ }^{[10]}$. Moreover, pro-inflammatory conditions associated with uremia found in ESRD patients can lead to irreversible premature aging of T-cells ${ }^{[12,13]}$. According to the $9^{\text {th }}$ annual study of the Egyptian Renal Registry submitted by the Egyptian Society of Nephrology and Transplantation ${ }^{[9]}$, the prevalence of ESRD in Egypt increased to 483 patients per million.

In this research, we aimed to explore the detection rates of the most common prevalent intestinal parasites in ESRD patients under HD maintenance in Benha University Hospital in order to prescribe early treatment to avoid severe life-threatening complications. 


\section{SUBJECTS AND METHODS}

This case-control research was conducted at Parasitology Department, Faculty of Medicine, Benha University, Egypt from August 2019 to December 2019.

Subjects: The study population included 57 ESRD patients attending HD unit in Benha University Hospital, with no other immunosuppressive condition; and 60 apparently healthy individuals as control group (from the surrounding individuals including nurses) without history of kidney problems or any other immunosuppressive condition (Table 1). Age ranged from 20 to70 in both groups. In ESRD group, 34 were males, 23 were females, and 38 of them were from rural areas. In the control group, sex distribution was equal and 26 of them were from rural areas. The exclusion criteria included all participants who, one month before the research, had not obtained any anti-parasitic medications.

Table 1. Important socio-demographic characteristics among the studied groups.

\begin{tabular}{llcc}
\hline \hline & & $\begin{array}{c}\text { HD patients } \\
\text { (n=57) }\end{array}$ & $\begin{array}{c}\text { Control group } \\
(\mathbf{n = 6 0 )}\end{array}$ \\
\hline \multirow{2}{*}{ Sex } & Male & $34(59.65 \%)$ & $30(50 \%)$ \\
& Female & $23(40.35 \%)$ & $30(50 \%)$ \\
\multirow{2}{*}{ Age } & $\mathbf{2 1 - 3 0}$ & $13(22.8 \%)$ & $15(25 \%)$ \\
& $<\mathbf{3 0}$ & $44(77.2 \%)$ & $45(75 \%)$ \\
\multirow{2}{*}{ Residence } & Average & $52.3 \pm 11.6$ & $49.1 \pm 7.3$ \\
& Urban & $19(33.3 \%)$ & $34(56.67 \%)$ \\
Total & Rural & $38(66.7 \%)$ & $26(43.33 \%)$ \\
\hline \hline
\end{tabular}

Stool examination: From all study groups, three consecutive fresh fecal samples were collected in tight-fitting, dry-clean containers labelled with the name and transported immediately for analysis to the Benha University Parasitology Department. Direct stool examination was performed by wet ${ }^{[14]}$ and iodinestained smears ${ }^{[15]}$. For the screening of ova and other stages of various intestinal parasites, the formol-ether concentration technique was also conducted ${ }^{[16]}$. For each sample, permanent smear was prepared from sediments using the formol-ether technique and stained with modified Ziehl-Neelsen (MZN) for entric coccidian and Cryptosporidium spp. detection ${ }^{[16]}$. Slides were examined under light microscopy at X10, X40 and X100 magnifications.

Statistical analysis: Data analysis was carried out using the SPSS software version 21 (SPSS, Chicago, IL, USA). The Chi square test was used to compare prevalence of parasites among groups. Associations were tested using odd ratios (OR) and 95\% confidence intervals (CI) after adjustments. Statistical significance was considered when $P$ value $<0.05$.

Ethical considerations: Official permission of study was obtained from the concerned department (Internal Medicine Department of Benha University). All participants agreed to share in accordance with the ethical standards and an informed consent was obtained. Infected participants were informed and accordingly treated.

\section{RESULTS}

The overall parasite infection rate was $68.4 \%$ in patients with ESRD and $48.3 \%$ in controls and the discrepancy between the two groups was statistically significant $(P=0.024)$. Regarding entero-parasitosis (Table 2, and figure 1), E. histolytica/E. dispar was the commonest parasite compared to others, but the difference was not significant compared to control group. There was also no statistically relevant difference in both groups with respect to G. lamblia, $A$. lumbricoides and E. vermicularis infections. In four ESRD patients, Cryptosporidium spp. was detected while it was not detected in any subject in the control group and the relationship was statistically significant $(P<0.001)$.

Regarding intestinal complaints, associated diarrhea was present in 23/57 (40.3\%) of the HD group. No statistically significant difference was recorded between diarrheic and non- diarrheic patients according to type of parasite detected except in $E$. vermicularis infection which did not cause diarrhea in ESRD patients as shown in table (3).

Table 2. Rate of parasite infection in ESRD patients undergoing HD compared to the control group.

\begin{tabular}{|c|c|c|c|}
\hline Parasite detected & $\begin{array}{l}\text { HD group } \\
(\mathrm{n}=57)\end{array}$ & $\begin{array}{l}\text { Control group } \\
(n=60)\end{array}$ & $\begin{array}{c}\text { Statistical analysis } \\
P \text { value }\end{array}$ \\
\hline \multicolumn{4}{|l|}{ Protozoa } \\
\hline E. histolytica/E. dispar & $23(40.3 \%)$ & $21(35 \%)$ & 0.980 \\
\hline G. Iamblia & $6(10.53 \%)$ & $3(5 \%)$ & 0.262 \\
\hline Cryptosporidium spp. & $4(7 \%)$ & $0(0 \%)$ & $<0.001 *$ \\
\hline \multicolumn{4}{|l|}{ Helminths } \\
\hline A. lumbricoides & $4(7 \%)$ & $3(5 \%)$ & 0.646 \\
\hline E. vermicularis & $2(3.51 \%)$ & $2(3.33 \%)$ & 0.648 \\
\hline Total & $39(68.4 \%)$ & $29(48.3 \%)$ & $0.024^{*}$ \\
\hline Significant & & & \\
\hline
\end{tabular}




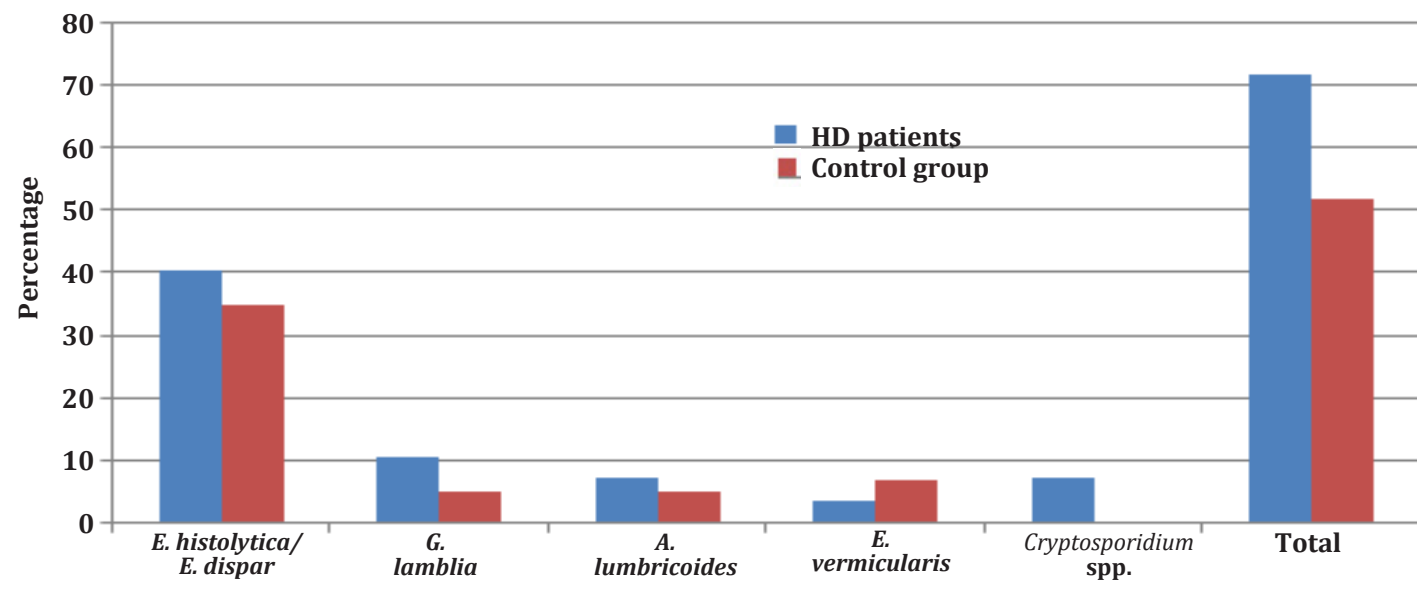

Fig 1: Rate of parasitic infections in ESRD patients undergoing HD compared to the control group.

Table 3. Association between the presence of intestinal parasites and diarrhea in ESRD patients.

\begin{tabular}{lccc}
\hline \hline Parasite detected & $\begin{array}{c}\text { ESRD patients with diarrhea } \\
\text { (No. = 23) }\end{array}$ & $\begin{array}{c}\text { ESRD patients without diarrhea } \\
\text { (No. = 16) }\end{array}$ & $\begin{array}{c}\text { Statistical analysis } \\
\text { P value }\end{array}$ \\
\cline { 2 - 3 } & No. (\%) & No. (\%) & 0.058 \\
\hline Protozoa & $15(65.2 \%)$ & $8(50 \%)$ & 0.67 \\
E. histolytica/E. dispar & $4(17.4 \%)$ & $2(12.5 \%)$ & 0.12 \\
G. lamblia & $4(17.4 \%)$ & $0(0 \%)$ & 0.16 \\
Cryptosporidium spp. & & & $\mathbf{0 . 0 2}$ \\
Helminths & $0(0 \%)$ & $2(12.5 \%)$ & \\
A. lumbricoides & $0(0 \%)$ & $4(25 \%)$ & \\
E. vermicularis & &
\end{tabular}

*Significant

\section{DISCUSSION}

Severe complications or even death among immunocompromised patients, including ESRD patients, have been reported in relation to intestinal parasites, especially opportunistic types ${ }^{[17]}$. Studies to establish the prevalence of IPIs in ESRD patients under HD are uncommon in Egypt, generally and specifically in our locality ${ }^{[18-20]}$.

The objective of our research was to investigate the prevalence of common intestinal parasites in patients with ESRD maintained on HD in Benha University Hospital. Documented results showed that the total rate of parasite infection was $68.4 \%$ in HD patients vs. $48.3 \%$ in control group. Difference between the two groups was of statistical significance $(P=0.024)$. It is interesting that protozoa infection was more prevalent than helminthic infection in our sample of ESRD patients. Similarly, Shehata et $a{ }^{[21]}$ reported a significantly higher detection rate of IPIs in patients with ESRD compared to healthy persons (52.5\% vs. $12 \%$, respectively). In another study, higher rate of parasitic infection was found in HD patients when compared to the control ( $43.7 \%$ vs $12.7 \%$, respectively) ${ }^{22]}$. Also, Elkady et al. ${ }^{[19]}$ reported high prevalence of enteroparasitosis in ESRD patients (66\%) compared to $26 \%$ in the healthy control group.
In our study, according to the associated parasite infection, E. histolytica/E. dispar was the most predominant parasite in ESRD patients followed by $G$. lamblia, and Cryptospiridium spp (40\%, 10\% and 7\% respectively). In accordance with our results, analysis of 111 stool samples by Botero et al. ${ }^{[23]}$ from patients with suppressed immunity revealed E. histolytica/E. dispar in eleven samples, G. lamblia in eight samples, Cryptosporidium spp. in four, and Microsporidia spp. in two samples.

In contrast, Elkady et al. ${ }^{[19]}$ reported that protozoa identified from stool testing in patients with ESRD and the control group were C. parvum $(40 \%$ and $6 \%$, respectively), E. histolytica/E. dispar (14\% and $16 \%$, respectively), and G. lamblia $(12 \%$ and $4 \%$, respectively). Out of 110 stool samples from ESRD patients investigated by Gil et al. ${ }^{[17]}, 57$ (51.8\%) screened positive for intestinal parasites. Parasites were documented as Cryptosporidium spp. (26.4\%), Blastocystis spp. (24.5\%), Endolimax nana (20.0\%), Entamoeba coli (6.4\%), E. histolytica/E. dispar (3.6\%), G. lamblia (0.9\%), and S. stercoralis (0.9\%).

In our study, cryptosporidiosis was detected in only $7 \%$ of ESRD patients and in none from the control 
group $(P<0.001)$. Seyrafian et al. ${ }^{[24]}$ confirmed that Cryptosporidium spp. was among the IPIs identified in their ESRD patients. A frequency of $11.5 \%$ was found, which was higher than in our evaluation. However, our result is higher than that observed in Brazil (4.6\%) by Kulik et al. ${ }^{[25]}$ and lower than that reported in Turkey (20.2\%) by Turecapar et al. ${ }^{[26]}$. Cryptosporidiosis may cause extreme chronic diarrhea, resulting in electrolyte imbalance, malabsorption and profound weight loss in immunosuppressed individuals including ESRD patients ${ }^{[27]}$. In the present research, 23 (59\%) of the infected ESRD patients presented with diarrhea while $16(41 \%)$ did not have diarrhea which correlated with Botero et al. ${ }^{[21]}$ who reported that from their studied immunocompromised patients, 58 (52.3\%) presented abdominal pain and diarrhea while 53 (47.7\%) gave no clinical manifestation associated with the gastrointestinal tract.

In conclusion, our study results showed that intestinal parasitosis was more common in ESRD patients with HD than in the matched control group. Since patients under HD are immunocompromised, owing to their weakened immune system, intestinal parasites can cause life-threatening conditions. so, routine interval stool examination and early detection and treatment of intestinal parasitosis is important in this category of patients.

Authors' contributions: Elkholy AA designed and performed the experiments; El-Badawy AM and Mansour AE collected data and samples from the patients, analyzed the data and revised the manuscript. All authors revised and approved the final manuscript.

Competing interest: The authors declare that there are no competing interests.

Funding statement: The research was not funded by any institution in Egypt.

\section{REFERENCES}

1. Garcia LS. Intestinal protozoa (coccidian and microsporidia) and algae. Diagnostic Medical Parasitology $5^{\text {th }}$ ed. ASM 2007; 57-101.

2. Stark D, Barrat JL, VanHal S, Marriott D, Harkness J, Ellis JT. Clinical significance of enteric protozoa in immunosuppressed human population. Clin Microbiol Rev 2009; 22:643-650.

3. Haque R. Human intestinal parasites. JHPN 2007; 25, 387.

4. Shally A, DAP B, Lorenzo S . Helminthic infections. BMJ 2003; 327(7412):431-433.

5. Gentile G, Venditti M, Micozzi A, Caprioli A, Donelli G, Tirindelli C, et al. Cryptosporidiosis in patients with hematologic malignancies. Rev infect Dis 1991; 13: 842846.

6. Igra-siegman Y, Kapil AR, Sen P, Kaminski ZC, Louria DB. Syndrome of hyperinfection with Strongyloides stercoralis. Rev infect Dis 1981; 3:397- 407.
7. Sneller M, Clifford $H$. Infections in the immunocompromised host. In: RICH, R. Clinical immunology principles and practices. St Louis, Mosby 1996; p: 579-593.

8. Weber R, Bryan RT, Schwartz DA, Owen RL. Human microsporidial infections. Clin Microbiol Rev 1994; 7: 426-461.

9. El-Ballat MA, El-Sayed MA, Emam HKA. Epidemiology of end stage renal disease patients on regular hemodialysis in El-Beheira governorate, Egypt. EJHM 2019; 76(3):3618-3625.

10. Girndt M, Sester U, Sester M, Kaul H, Kohler H. Impaired cellular immune function in patients with end-stage renal failure. Nephrol Dial transplant 1999;14(12): 2807-2810.

11. Eleftheriadis T, Antoniadi G, Liakopoulos V, Kartsios C, Stefanidis I. Disturbances of acquired immunity in hemodialysis patients. Semin Dial 2007; 20(5):440451.

12. Meijers RW, Litjens NH, de Wit EA, Langerak AW, van der Spek A, Baan CC, et al. Uremia causes premature ageing of the $\mathrm{T}$ cell compartment in end-stage renal disease patients. Immun Ageing 2012; 9(1): 19.

13. Meijers RW, Betjes MG, Baan CC, Litjens NH. T-cell ageing in end-stage renal disease patients: assessment and clinical relevance. World J Nephrol 2014; 3(4): 268-276

14. Fleck SL, Moody AH. Diagnostic technique in Medical Parasitology. $1^{\text {st }}$ Edition. Butterworth \& Co. (Publishers) Ltd 1988; 22-26.

15. Cheesbrough M. Medical Laboratory Manual for Tropical Countries. ELBS Tropical Health Technology Butterworth 1987; 561-564.

16. Cheesbrough M. District laboratory practice in tropical countries. Part I, Cambridge University press. Low Price Editions 2007; pp. 196- 207.

17. Gil FF, Barros MJ, Macedo NA, Júnior GEC, Redoan R, Busatti $\mathrm{H}$, et al. Prevalence of intestinal parasitism and associated symptomatology among hemodialysis patients. Rev Inst Med Trop Sao Paulo 2013; 55:6974.

18. Ali MS, Mahmoud LA, Abaza BE, Ramadan MA. Intestinal spore-forming protozoa among patients suffering from chronic renal failure. J Egypt Soc Parasitol 2000; 30(1):93-100.

19. El-Kady AM, FahmiY, Tolba M, Hashim AA, Hassan AA. Cryptosporidium infection in chronic kidney disease patients undergoing hemodialysis in Egypt J Parasitic Dis 2018; 42(4):630-635.

20. Fahmi YA, Merghany ME, Hashim AA, ElKady AM. Entameba histolytica as a cause of diarrhea in hemodialysis patients in Qena. SVUIJM 2018; 7(1):3235.

21. Shehata AI, Hassanein F, Abdul-Ghani R. Opportunistic parasitosis among Egyptian hemodialysis patients in relation to $\mathrm{CD} 4^{+} \mathrm{T}$-cell counts: a comparative study. BMC Infect Dis 2019; 19(1):480.

22. Karadag G, Tamer GS, Dervisoglu E. Investigation of intestinal parasites in dialysis patients. Saudi Med J 2013; 34(7):714-718. 
23. Botero JH, Castano A, Montoya MN, Ocampo NE, Hurtado MI, Lopera MM. A preliminary study of the prevalence of intestinal parasites in immunocompromised patients with and without gastrointestinal manifestations. Rev Inst Med Trop Sao Paulo 2003; 45:197-200.

24. Seyrafian S, Pestehchian N, Kerdegari M, Yousefi HA, Bastani B. Prevalence rate of Cryptosporidium infection in hemodialysis patients in Iran. Hemodial Int 2006; 10: 375-379.

25. Kulik RA, Falavigna DL, Nishi L, Araujo SM. Blastocystis spp. and other intestinal parasites in hemodialysis patients. Braz J Infect Dis 2008; 12: 338-341.
26. Turkcapar N, Kutlay S, Nergizoglu G, Atli T, Duman N. Prevalence of Cryptosporidium infection in hemodialysis patients. Nephron 2002; 90:344-346.

27. Nkenfou CN, Nana CT, Payne VK. Intestinal parasitic infections in HIV infected and non-infected patients in a low HIV prevalence region, West-Cameroon. PLoS One 2013; 8: e57914. 